\title{
Detection of Penicillium aurantiogriseum by ELISA utilizing antibodies produced against its exoantigens
}

\author{
Ping Lu, $\nmid$ R. R. Marquardt, ${ }^{1}$ A. A. Frohlich ${ }^{1}$ and J. T. Mills ${ }^{2}$ \\ Author for correspondence: R. R. Marquardt. Tel: +1 204474 8188. Fax: +1 2042750402.
}

1 Department of Animal Science, University of Manitoba, Winnipeg, Manitoba R3T 2N2, Canada

2 Winnipeg Research Centre, Agriculture and Agri-Food Canada, Winnipeg, Manitoba R3T 2M9, Canada

\begin{abstract}
An indirect competitive ELISA was developed using rabbit antiserum against the exoantigens (ExAgs) of Penicillium aurantiogriseum, and cross-reactivities were determined with 15 ExAgs from other species and genera of fungi and with the water-soluble extracts from four grains. The assay had good sensitivity to $P$. aurantiogriseum ExAgs ( $1 \mu \mathrm{g}$ per $\mathrm{ml}$ serum), with generally low or no cross-reactivity with grain extracts and the other fungi, including five species of Penicillium, four species of Aspergillus, three species of Fusarium, two species of Mucor and one species of Alternaria. Immunoblotting analysis of the ExAgs from $P$. aurantiogriseum yielded at least $\mathbf{2 0}$ distinct antigenic bands, with about 3 or 4 being dark, 10-12 light and 5-8 faint in colour. Most of the bands had molecular masses of about 70-90 kDa. In contrast to $P$. aurantiogriseum, the ExAgs from the other fungi either did not react in the immunoblotting assay with the antiserum, or reacted only weakly with it. One antigenic band from $P$. roqueforti, however, reacted moderately strongly with the antiserum. The ELISA and immunoblotting analysis were used to detect $P$. aurantiogriseum in naturally contaminated wheat samples, and in wheat samples spiked with a second common storage fungus, Aspergillus ochraceus. The results demonstrated that the antiserum was able to detect $P$. aurantiogriseum in a background of other fungal species, and that these did not produce false positives. There was also a positive association between the concentration of $P$. aurantiogriseum ExAgs, as measured by ELISA, and the amount of mould as determined by the number of colony-forming units. Immunoblotting qualitatively confirmed the ELISA results obtained with fungi when cultured on liquid or on solid (wheat) media. The data suggest that the immunoassays developed for $P$. aurantiogriseum are useful for the detection and identification of $P$. aurantiogriseum on the basis of its ExAgs, with the advantages of being more efficient, simple and reliable than conventional techniques.
\end{abstract}

Keywords: Penicillium aurantiogriseum, ELISA, exoantigens, immunoblotting

\section{INTRODUCTION}

Mould contamination can not only cause deterioration of foods and feeds, but can adversely affect human and animal health since toxic metabolites, or mycotoxins, may be produced. The latter is of increasing concern as many different fungi have been shown to produce one or more

†Present address: Animal Diseases Research Institute, 3851 Fallowfield Road, PO Box 11300, Station H, Nepean, ON K2H 8P9, Canada.

Abbreviations: ExAg, exoantigen; OA, ochratoxin A. mycotoxin (CAST, 1989). The three major genera of mycotoxin-producing fungi are Aspergillus, Penicillium and Fusarium. Fusaria invade food and feed supplies mainly during production and processing, and are defined as field fungi. Aspergilli and penicillia, in contrast, mainly grow on foods and feeds during storage, and are referred to as storage fungi (CAST, 1989). These two genera include most of the economically important fungi as they are ubiquitous, can cause food spoilage and bio-deterioration, and are capable of producing many different mycotoxins (Pitt \& Hocking, 1985; Pitt \& Samson, 1990). Penicillium spp. are particularly abundant and have 
been shown to produce secondary metabolites belonging to five metabolite families (Lund \& Frisvad, 1994). It is therefore necessary, not only to quantitatively monitor for mould contamination in foods and feeds, but also to accurately and reliably identify the fungi, as specific moulds are associated with the production of specific families of mycotoxins, each having different properties (Frisvad, 1988, 1989). Traditional fungal taxonomy, based primarily on morphology and growth characteristics, is generally considered to be tedious and time-consuming, and can lead to erroneous identification, even for experienced workers. This problem is serious, particularly with penicillia, as the large number of species, and their similar morphology, make identification especially difficult (Pitt \& Samson, 1990; Samson \& Frisvad, 1991). Conventional mould detection techniques include the use of culture methods, electrical measurements, microscopy and analyses for enzymes, chitin or other fungal components. These techniques suffer from low sensitivity and lack of specificity (Jarvis et al., 1983; Notermans \& Heuvelman, 1985; Jarvis \& Williams, 1987).

Pitt \& Samson (1990) have reviewed new approaches for Aspergillus and Penicillium systematics, and consider none of them to be sufficiently accurate when used alone for the detection and identification of storage fungi. Kaufman \& Standard (1987) reported that the ExAgs, a soluble mixture of extracellular fungal products, could be used as indicators of the presence of fungal species or genera. They produced antibodies against the ExAgs of medically important fungi and assayed them by immunodiffusion. This method, however, is relatively insensitive and requires a large quantity of antibody. Immunoassays (ELISAs) have been developed for detecting and identifying several species of moulds but with variable success (Notermans \& Heuvelman, 1985; Lin et al., 1986; Notermans et al., 1986; Dewey et al., 1990; Fuhrmann et al., 1990, 1992; Tsai \& Cousin, 1990; Banks et al., 1993). Currently only a few ELISAs have been developed that can specifically and quantitatively detect the presence of the common storage fungi (Dewey et al., 1990). Therefore, there is a need for immunoassays that are not only capable of identifying the presence of the most common Penicillium species, but also of estimating their content in grain. $P$. aurantiogriseum, being the most common Penicillium species, was selected as a model fungus for determining whether ExAgs could be utilized in an ELISA. ExAgs of $P$. aurantiogriseum were prepared and tested by indirect competitive ELISA and SDS-PAGE, followed by Western blotting. A rapid, specific and sensitive assay for detecting and identifying $P$. aurantiogriseum was developed utilizing these ExAgs. The assay was capable of detecting $P$. aurantiogriseum in grain.

\section{METHODS}

Sources of fungi and grain. Isolates of Penicillium aurantiogriseum Dierckx, nos 798, 832 and 3298, were provided by $\mathrm{Dr}$ G. Platford, Plant Pathology Laboratory, Manitoba Agricultural Services Complex, Winnipeg MB. Isolate no. 3298 was used for all studies and isolate IBT 3471, obtained from Dr J. Frisvad, Department of Biotechnology, The Technical Uni- versity of Denmark, DK-2800, Lyngby, Denmark, was the standard reference strain. Cultures of Aspergillus ocbraceus Wilhelm (NRRL 3174) and A. versicolor (Vuill.) Tiraboschi (NRRL 573) were pure cultures maintained in our laboratory. Isolates of Fusarium poae (Peck) Wollenw, F. avenaceum ( $F r$.) Sacc., F. equiseti (Corda) Sacc., Mucor species and Alternaria alternata (Fr.) Keissler were provided by Mr R. M. Clear, Canadian Grain Commission, Grain Research Laboratory, Winnipeg MB. Cultures of Aspergillus candidus Link (ATCC 44054), A. flavus var. columnaris Link (A TCC 44310), Penicillium chrysogenum Thom (IBT 3359), P. commune Thom (IBT 10501) and $P$. roqueforti var. roquefort $i$ Thom (IB'T 5229) were provided by Dr J. T. Mills, Agriculture Canada, Winnipeg Research Centre. The identities of Penicillium species were confirmed using procedures described by Frisvad \& Filtenborg (1989) and Mills et al. (1994). Grains and soybean were from local sources and did not contain any visible fungal biomass.

Materials. The following were purchased: potato dextrose agar and yeast extract from Becton Dickinson; microtitre plates (Falcon 3911 Microtest III Flexible Assay Plates; Becton Dickinson); ammonium sulfate from Fisher Scientific Chemical; Whatman no. 1 filter paper from Whatman; sterile filters from Nalgene, Nalge; Minicon CS-15 spinal fluid concentrator from Amicon; reagents for preparing PBS from Mallinckrodt Canada; and the ultra-pure reagents for electrophoresis and immunoblotting from ICN, Schwarz/Mann Biotech and BioRad. Other reagents were from Sigma. All solvents and reagents were of analytical grade. The microplate reader (model 450), electrophoresis tank (Mini-PROTEAN II) and electroblotting device (Transblot SD Semi-Dry Transfer Cell) were from BioRad.

Preparation of ExAgs. ExAgs from all the fungal species listed above were prepared according to Standard et al. (1985) with some modifications. Briefly, fungal spores from different genera that had been propagated on potato dextrose agar were used to inoculate sucrose-yeast-mineral (SYM) liquid medium. After two weeks of growth at $30^{\circ} \mathrm{C}$, the mycelia were separated from the liquid medium by filtration through two layers of Whatman no. 1 filter paper. Filtrates were freeze-dried and stored at $-20^{\circ} \mathrm{C}$. The freeze-dried material that was used for immunization or ELISA was redissolved in $0.1 \mathrm{M}$ PBS $(0.1 \mathrm{M}$ sodium phosphate, $0 \cdot 145 \mathrm{M} \mathrm{NaCl}, \mathrm{pH} 7 \cdot 2$ ), dialysed for 24 h against five changes of PBS and concentrated in a Minicon. Particulate matter was removed by centrifuging at $20000 \mathrm{~g}$ for $30 \mathrm{~min}$ at $4^{\circ} \mathrm{C}$. The antigen preparation used for the ELISA was aliquoted and stored at $4{ }^{\circ} \mathrm{C}$ with the addition of $0.01 \%(\mathrm{w} / \mathrm{v})$ Thimerosal (sodium ethylmercurithiosalicylate). Thimerosal-free antigens used for immunization were sterilized by passing through a $0.22 \mu \mathrm{m}$ filter. These preparations were referred to as ExAgs. The protein concentration of these and other samples was determined using the procedure of Bradford (1976).

Extracellular protein and extracellular polysaccharide antigens were prepared from ExAgs by ammonium sulfate precipitation (Tsai \& Cousin, 1990). Briefly, the freeze-dried ExAgs of $P$. aurantiogriseum were redissolved in PBS and the proteins were precipitated by adding ammonium sulfate to $80 \%$ saturation. The precipitate was redissolved in PBS. This fraction, and the supernatant containing polysaccharides, were dialysed against saline and concentrated. Sugar quantification was performed according to the method of Dubois et al. (1956).

Preparation of water extracts of grain. Clean wheat, barley, maize and soybean samples were ground using a Cyclotec sample mill equipped with a $1 \mathrm{~mm}$ screen (Tecator); $50 \mathrm{~g}$ of the ground sample was mixed with $100 \mathrm{ml} \mathrm{SYM} \mathrm{liquid} \mathrm{medium} \mathrm{and} \mathrm{shaken}$ vigorously for $1 \mathrm{~h}$ on a wrist action shaker (model 75, Burrell). 
The suspensions were centrifuged at $20000 \mathrm{~g}$ at $4{ }^{\circ} \mathrm{C}$ for $30 \mathrm{~min}$, and the supernatants were carefully removed, concentrated and aliquoted. All stock antigen preparations were stored at $-20^{\circ} \mathrm{C}$; the working solutions were stored at $4{ }^{\circ} \mathrm{C}$.

Immunization and preparation of antibody. Two rabbits (Dutch Belted, $1-1.5 \mathrm{~kg}$ body weight) were injected subcutaneously (three sites) with sterile ExAgs of P. aurantiogriseum isolate 3298. The antigen preparation was emulsified with complete Freund's adjuvant (first injection), or incomplete Freund's adjuvant (booster injections), and administered at a dosage of $1 \mathrm{mg}$ protein at 3-week intervals. Rabbits were bled at weekly intervals, starting one week after the third injection, and serum antibody response was assayed by immunodiffusion (Standard et al., 1985). The rabbit of choice was killed and exsanguinated when the desired antibody response was obtained, and serum was harvested, aliquoted and stored at $-80^{\circ} \mathrm{C}$.

ELISA titre assay. The protocols were those of Harlow \& Lane (1988). Briefly, microtitre plates were coated with $0 \cdot 1 \mu \mathrm{g}$ per well of P. aurantiogriseum ExAgs in $100 \mu \mathrm{l}$ PBS and incubated overnight at $4{ }^{\circ} \mathrm{C}$. After three washings with PBS containing $0.05 \%(\mathrm{v} / \mathrm{v})$ Tween 20 (PBST), the plates were blocked with $5 \%(\mathrm{w} / \mathrm{v})$ skimmed milk in PBS for $2 \mathrm{~h}$ at $37^{\circ} \mathrm{C}$. Serial dilutions of the antiserum $(100 \mu \mathrm{l}$ per well) together with the negative control serum (before immunization) were added to the plates, and after $2 \mathrm{~h}$ incubation at $37^{\circ} \mathrm{C}$ the plates were washed three times with PBST. The plates were incubated for an additional $1.5 \mathrm{~h}$ with goat anti-rabbit IgG conjugated to alkaline phosphatase. $p$-Nitrophenyl phosphate solution $(100 \mu \mathrm{l})$ was added after six washings with PBST, and the plates were read at $405 \mathrm{~nm}$. The optimal antigen and antibody concentrations for the competitive inhibition assay were determined using a checker-board titration assay.

Competitive inhibition assay. The procedures were essentially the same as those of the titre assay except that $50 \mu \mathrm{l}$ of a single fixed dilution of the antiserum $(1: 3000)$ was used after the addition of $50 \mu \mathrm{l}$ of fungal ExAgs. The protein concentration of the competing antigen was usually $0.5 \mathrm{mg} \mathrm{m}^{-1}$ for $P$. aurantiogriseum, and up to $10 \mathrm{mg} \mathrm{ml}^{-1}$ for antigens from other species. The concentration of ExAgs, expressed as concentration of proteins which inhibited $50 \%$ of the antibody binding, was calculated from the competitive-inhibition curve and referred to as the sensitivity (Tsai \& Cousin, 1990). The degree of reactivity (expressed as percentage cross-reactivity) of different fungal ExAgs to anti- $P$. aurantiogriseum serum was calculated by comparing the sensitivity of the fungal ExAgs with that of $P$. aurantiogriseum (scale set at 100). The assays were done twice in duplicate and the results were averaged.

Extracellular protein and extracellular polysaccharide antigens of $P$. aurantiogriseum were also tested as inhibiting antigens by applying them at known concentrations. Unfractionated $P$. aurantiogriseum ExAgs were used as the control. The sensitivity and reactivities were calculated on the basis of the protein and sugar concentrations of these fractions.

SDSPAGE and immunoblotting analysis. ExAgs were solubilized in $1.5 \%(\mathrm{w} / \mathrm{v})$ SDS at $100^{\circ} \mathrm{C}$ for $5 \mathrm{~min}$, and separated by SDS-PAGE according to the method of Laemmli (1970) using a $4-20 \%(\mathrm{w} / \mathrm{v}) \mathrm{T}$ gradient gel (Mini-PROTEAN II, Ready Gel, Bio-Rad). The pre-stained standard proteins (Bio$\mathrm{Rad})$ were myosin, $\beta$-galactosidase, phosphorylase $b$, BSA, ovalbumin, carbonic anhydrase, soybean trypsin inhibitor, lysozyme and aprotinin. Their respective molecular masses were $205,116.5,106,80,49 \cdot 5,32.5,27 \cdot 5,18.5$ and $6.5 \mathrm{kDa}$. The separated components were either visualized by silver staining or transferred onto nitrocellulose membranes $(0.22 \mu \mathrm{m}$, BioRad) in a semi-dry transblot cell using $25 \mathrm{mM}$ Tris, $192 \mathrm{mM}$ glycine buffer ( $\mathrm{pH} 8.3$ ) containing $20 \%(\mathrm{v} / \mathrm{v})$ methanol and $1.3 \mathrm{mM}$ SDS $(0.00375 \%)$. The membrane was washed for $1 \mathrm{~h}$ with TBS (20 mM Tris, $500 \mathrm{mM} \mathrm{NaCl}, \mathrm{pH} 7 \cdot 5)$ containing $10 \%$ methanol and blocked for $2 \mathrm{~h}$ with $3 \%(\mathrm{w} / \mathrm{v})$ BSA. After washing with TBS containing $0.05 \%(\mathrm{v} / \mathrm{v})$ Tween 20 (TBST), the membrane was incubated for $1.5 \mathrm{~h}$ with the antiserum (1:5000) diluted in TBST containing $1 \%(\mathrm{v} / \mathrm{v})$ gelatin (antibody buffer). The membrane was then incubated for $1 \mathrm{~h}$ in goat anti-rabbit IgG conjugated with alkaline phosphatase diluted $1: 8000$ in antibody buffer. Nitro blue tetrazolium and 5-bromo4-chloro-3-indolyl phosphate (BCIP, $p$-toluidine salt) were used as the substrate (Blake et al., 1984). All the incubations were at room temperature with agitation unless otherwise specified. Electrophoresis and electroblotting were performed following the manufacturer's instructions (Bio-Rad).

Detection of $\boldsymbol{P}$. aurantiogriseum ExAgs in wheat. Wheat samples were moisturized with distilled water to a final water content of $22 \%$ (w/w), inoculated with $0,10^{2}$ or $10^{5}$ A. ochraceus spores $\mathrm{g}^{-1}$, and incubated for up to $30 \mathrm{~d}$ at $30^{\circ} \mathrm{C}$. The number of replicates in each group was 15 . Five samples were taken from each group on days 0,7 and 30 , and were dried and ground as described above. The same samples were analysed for $P$. aurantiogriseum ExAgs using the ELISA and immunoblotting procedures, and for glucosamine (Rotter et al., 1989), ochratoxin A (OA) (Clarke et al., 1993), the number of c.f.u. (International Organization for Standardization, 1983a, b) and for type of mycoflora (Mills \& Wallace, 1979). The procedure for detecting $P$. aurantiogriseum ExAgs in wheat samples using the ELISA was the same as for the competitive inhibition assay, except that mouldy wheat extracts were used as the source of antigen. The wheat extracts were prepared by mixing $5 \mathrm{~g}$ of the wheat sample with $25 \mathrm{ml}$ PBS followed by vigorous shaking for $1 \mathrm{~h}$ and centrifuging at $20000 \mathrm{~g}$ for $45 \mathrm{~min}$. The supernatant was filtered (Whatman no. 1 filter paper) and used for the competitive inhibition assay along with appropriately diluted rabbit anti- $P$. aurantiogriseum serum. The concentration of ExAgs present in the grain extracts was calculated from the standard inhibition curves obtained during the same assay. Selected PBS extracts were also solubilized and analysed using the immunoblotting SDS-PAGE described for fungal ExAgs.

\section{RESULTS}

\section{Confirmation of the identity of $\boldsymbol{P}$. aurantiogriseum}

P. aurantiogriseum isolates 798,832 and 3298 had similar morphological and chemical characteristics to isolate IBT 3471 identified as $P$. aurantiogriseum Dierckx (Lund \& Frisvad, 1994). Agar plugs of isolates 798, 832 and 3298, when placed on TLC plates, exhibited light blue and light brown bands of aurantiamine and verrucosidin, respectively, in the same positions as those obtained with aurantiamine and verrucosidin standards and IBT 3471. Isolates 798,832 and 3298 were therefore confirmed to be $P$. aurantiogriseum Dierckx (Mills et al., 1994).

\section{Optimization of ELISA}

The checker-board titration assay showed that the optimal concentration of the coating antigens was $0.05-0.5 \mu \mathrm{g}$ protein per well. Optimal sensitivities were obtained when the antiserum dilutions were between $1: 3000$ and 1:6000 (data not shown). 


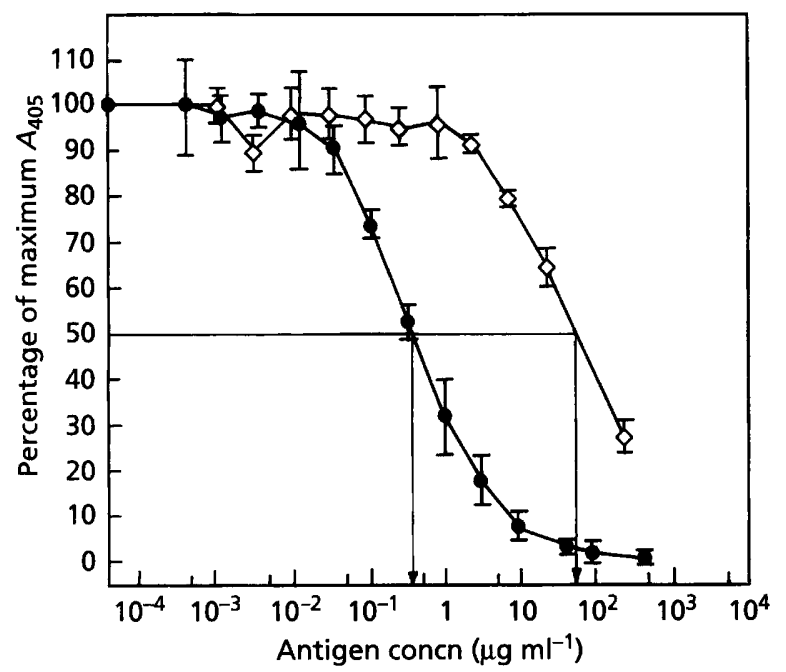

Fig. 1. Typical competitive inhibition curves of $P$. aurantiogriseum isolate $3298(O)$ and $P$. roqueforti $(\diamond)$ with rabbit antiserum raised against $P$. aurantiogriseum ExAgs. Arrows indicate the antigen concentration which caused a $50 \%$ reduction in antibody binding, and is the value used to denote sensitivity. Values represent mean \pm SD of duplicate assays. See Methods for further detail.

\section{Detection of specific ExAgs of $P$. aurantiogriseum by competitive ELISA}

Typical competitive inhibition curves obtained with rabbit serum against $P$. aurantiogriseum isolate 3298, and the ExAgs from two different species of Penicillium are illustrated in Fig. 1. A total of 16 ExAgs from five genera of fungi were used to test the specificity of the antibody (Table 1). Included were six species of Penicillium, four of Aspergillus, three of Fusarium, two of Mucor and one of
Alternaria, and three extracts from cereals and one from soybeans. The results demonstrated that the antiserum directed against $P$. aurantiogriseum ExAgs was highly reactive to the ExAgs of $P$. aurantiogriseum, reacted to a negligible degree with the ExAgs of the other fungal species ( $<5 \%$ cross-reactivity), and did not react with extracts from grain or soybeans. The sensitivity of the assay, for three duplicate assays, against $P$. aurantiogriseum ExAgs, as measured by the concentration of protein which inhibited antibody binding by $50 \%$, was approximately $1 \mu \mathrm{g} \mathrm{ml}^{-1}$, with the intra-assay coefficient of variation being $10 \%$ and that for inter-assay variation being $30 \%$. The lower limit of detection, which was calculated as the mean $\pm 2 \mathrm{SD}$ (i.e. $20 \%$ coefficient of variation), was approximately $50 \mathrm{ng} \mathrm{m}^{-1}$. The detection limits for the fungus itself would be approximately 4000 fold higher $\left(200 \mu \mathrm{g} \mathrm{ml}^{-1}\right)$ as the ExAgs comprised only a small portion of total fungal mass [i.e. $0.26 \pm 0.05 \mathrm{mg}$ ExAgs (g fungal dry mass) ${ }^{-1}$.

\section{Composition of ExAgs as determined by silver staining and immunoblotting}

Silver staining profiles of the ExAgs from different fungal species yielded more than 20 bands (data not shown). Immunoblotting analysis of the ExAgs from three different isolates of $P$. aurantiogriseum revealed several distinct bands (Fig. 2). The immunoblotting and the silver staining (data not shown) profiles of the three isolates were similar. The molecular masses of these bands varied from less than $18.5 \mathrm{kDa}$ to more than $106 \mathrm{kDa}$, with approximately 3 or 4 yielding dark bands, 10-12 light bands and 5-8 faint bands. Most of the immunodominant bands were between about 70 and $90 \mathrm{kDa}$. Individual band intensity varied somewhat among the different isolates of $P$. aurantiogriseum. In contrast to the above results, the reaction of the antiserum with the ExAgs from

Table 1. Cross-reactivities of different ExAgs with rabbit antiserum raised against the ExAgs of $P$. aurantiogriseum isolate 3298

Cross-reactivity was calculated from the competitive inhibition curve by comparing the sensitivity (antigen concentration that caused $50 \%$ reduction in antibody binding) of different fungal antigens with that of P. aurantiogriseum (taken as $100 \%$ ). Values represent mean \pm SD of two assays carried out in duplicate. See Methods for further detail.

\begin{tabular}{|lclc|}
\hline ExAgs & $\begin{array}{c}\text { Cross-reactivity } \\
(\mathbf{\%})\end{array}$ & \multicolumn{1}{c|}{ ExAgs } & $\begin{array}{c}\text { Cross-reactivity } \\
\mathbf{( \% )}\end{array}$ \\
\hline P. aurantiogriseum & 100 & F. avenaceum & $1 \cdot 0 \pm 0$ \\
P. chrysogenum & $0 \cdot 1 \pm 0 \cdot 03$ & F. equiseti & $1 \cdot 0 \pm 0$ \\
P. citrinum & $0 \cdot 5 \pm 0 \cdot 4$ & F. poae & $0 \cdot 2 \pm 0$ \\
P. commune & $0 \cdot 2 \pm 0 \cdot 01$ & Mucor sp. 1 & $1 \cdot 0 \pm 0$ \\
P. roqueforti & $0 \cdot 9 \pm 0$ & Mucor sp. 2 & $1 \cdot 0 \pm 0$ \\
P. verrucosum & $0 \pm 0$ & Al. alternata & $4 \cdot 8 \pm 1 \cdot 9$ \\
A. candidus & $0 \cdot 7 \pm 0 \cdot 3$ & Barley extract & $0 \pm 0$ \\
A. flavus & $1 \cdot 0 \pm 0$ & Maize extract & $0 \pm 0$ \\
A. ochraceus & $4 \cdot 5 \pm 0 \cdot 1$ & Soy extract & $0 \pm 0$ \\
A. versicolor & $0 \cdot 7 \pm 0 \cdot 3$ & Wheat extract & $0 \pm 0$ \\
\hline
\end{tabular}




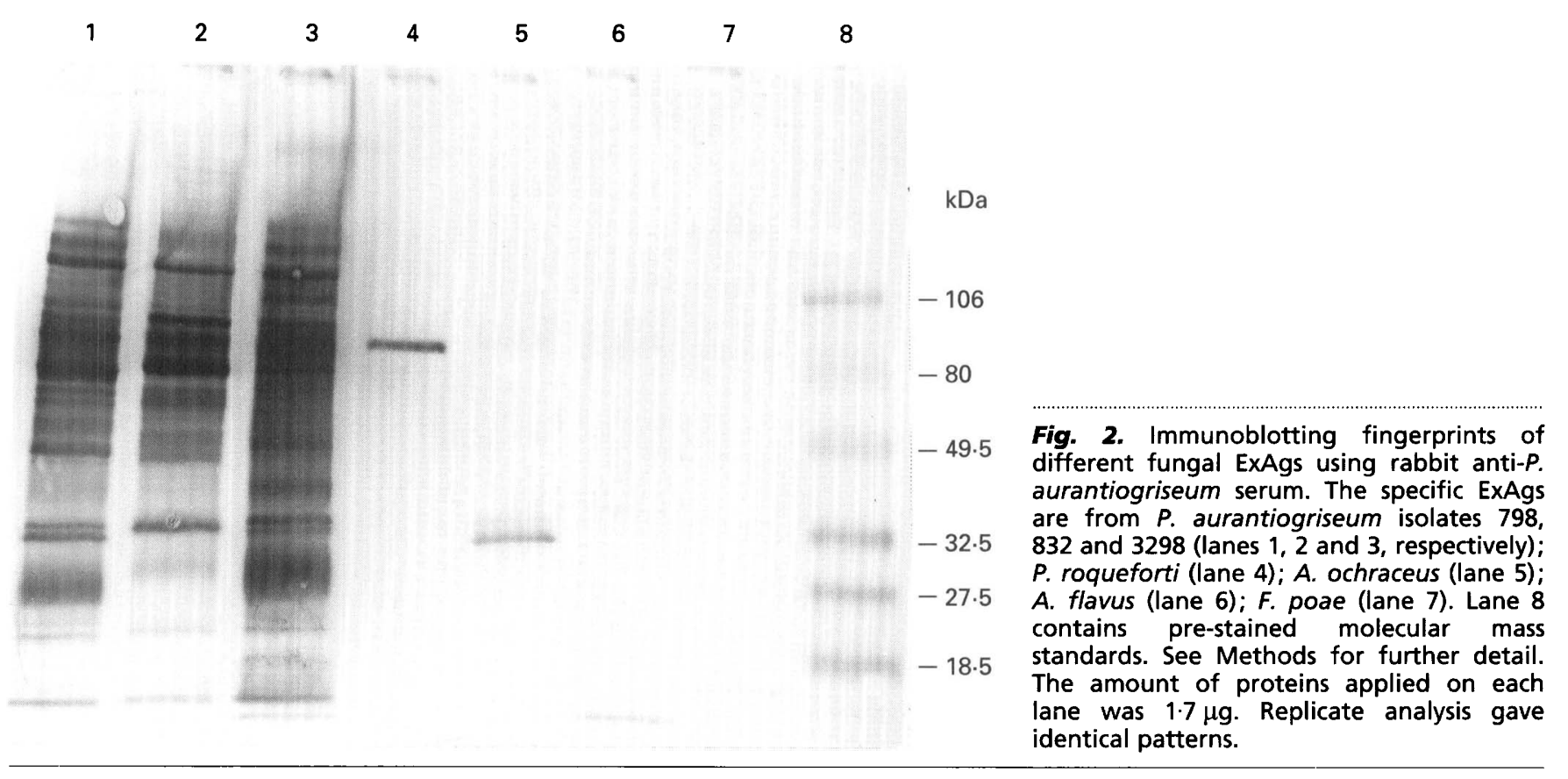

Table 2. Inhibition of $P$. aurantiogriseum isolate 3298 ExAg fractions containing different amounts of protein and carbohydrate by anti-P. aurantiogriseum serum

\begin{tabular}{|c|c|c|c|c|c|c|c|}
\hline \multirow[t]{2}{*}{$\begin{array}{l}\text { ExAgs } \\
\text { fraction }\end{array}$} & \multirow[t]{2}{*}{$\begin{array}{l}\text { Protein } \\
\left(\mu g \mathrm{l}^{-1}\right)\end{array}$} & \multirow[t]{2}{*}{$\begin{array}{c}\text { Carbohydrate } \\
\left(\mu \mathrm{gl}^{-1}\right)\end{array}$} & \multirow{2}{*}{$\begin{array}{l}\text { Protein: } \\
\text { carbohydrate } \\
\text { ratio }\end{array}$} & \multicolumn{2}{|c|}{$\begin{array}{l}\text { Sensitivity* } \\
\left(\mu g \mu^{-1}\right)\end{array}$} & \multicolumn{2}{|c|}{$\begin{array}{c}\text { Cross-reactivity } \dagger \\
(\%)\end{array}$} \\
\hline & & & & Protein & Carbohydrate & Protein & Carbohydrate \\
\hline Crude extract & $0 \cdot 12$ & 17 & 0.007 & 0.0002 & 0.001 & 100 & 100 \\
\hline Carbohydrate & 0.03 & 11 & 0.003 & ND & 0.004 & $\mathrm{ND}$ & 25 \\
\hline Protein & $0 \cdot 12$ & 0.5 & 0.24 & 0.0003 & ND & 67 & ND \\
\hline
\end{tabular}

ND, Not done.

* Concentration of protein or carbohydrate required to cause $50 \%$ inhibition of antibody binding. See Table 1 and Methods for further detail.

† See legend to Table 1.

the other species of fungi was negligible. Only one band from $P$. roqueforti (approximately $80 \mathrm{kDa}$, lane 4 ) reacted with the antiserum, with traces of the same band being observed with $A$. ocbraceus, $A$. flavus and $F$. poae ExAgs (lanes 5-7). Two bands from $A$. ocbraceus (lane 5) of approximately 32 and $34 \mathrm{kDa}$ also reacted either moderately or weakly, respectively, with the antibody. One band from each of $A$. flavus (lane 6) and F. poae (lane 7) ExAgs, having respective molecular masses of approximately $14 \mathrm{kDa}$ and $16 \mathrm{kDa}$, reacted slightly with the antibody.

\section{Competitive properties of ammonium-sulfate- fractionated antigens}

Ammonium-sulfate-precipitated ExAgs from $P$. aurantiogriseum had the same concentration of protein $(0 \cdot 12 \mu \mathrm{g}$ $\mu^{-1}$ ) as that of the unfractionated sample, but the ExAg carbohydrate concentration of the precipitated fraction was 35 -fold lower $\left(0.5\right.$ vs $\left.17 \mu \mu^{-1}\right)$. The supernatant fraction had a similar content of carbohydrates (11 vs $\left.17 \mu \mathrm{g} \mu \mathrm{l}^{-\mathbf{1}}\right)$ and fourfold reduced content of protein $(0 \cdot 03$ vs $0 \cdot 12 \mu{\mathrm{g} \mathrm{l}^{-1}}^{-1}$. Removal of the majority of carbohydrates from the extract only slightly increased the concentration of extract required to achieve the same degree of inhibition (i.e. sensitivity, 0.0003 vs $0.0002 \mu \mathrm{g}$ protein $\mu \mathrm{l}^{-1}$, Table 2 ). In contrast, when the sensitivity of the carbohydrate-rich supernatant was compared with that of the unfractionated extract, there was a fourfold decrease in sensitivity $(0.004$ vs $0.001 \mu \mathrm{g}$ carbohydrate $\mu \mathrm{l}^{-\mathbf{1}}$ ), which also corresponded to a fourfold decrease of protein in the sample. The latter effect may therefore be primarily attributed to the residual protein that remained in the supernatant fraction, and not to the carbohydrate component. These results suggest 
Table 3. Percentage of samples infected with the indicated fungi before and after incubation on non-sterilized and moisturized wheat that was inoculated with different concentrations of $A$. ochraceus spores

Wheat samples were moisturized with distilled water to a final water content of $22 \%(\mathrm{w} / \mathrm{w})$ and conditioned overnight at $4{ }^{\circ} \mathrm{C}$. Results were obtained from Whatman no. 1 filter paper culture as outlined in Methods. Values represent mean \pm sD for 3 replicates.

\begin{tabular}{|c|c|c|c|c|c|}
\hline \multirow{4}{*}{$\begin{array}{l}\text { Species or genus } \\
\text { of fungi identified }\end{array}$} & \multirow{4}{*}{$\begin{array}{c}\text { Incubation } \\
\text { (d) }\end{array}$} & \multicolumn{4}{|c|}{ Percentage of samples infected } \\
\hline & & \multirow{3}{*}{$\begin{array}{l}\text { Control } \\
\text { wheat* }\end{array}$} & \multicolumn{3}{|c|}{ Incubated wheat } \\
\hline & & & \multicolumn{3}{|c|}{ No. of A. ochraceus spores $\mathrm{g}^{-1}$ : } \\
\hline & & & 0 & $10^{2}$ & $10^{5}$ \\
\hline \multirow[t]{3}{*}{ Penicillium } & 0 & $53 \pm 1$ & $21 \pm 15$ & $41 \pm 29$ & $42 \pm 24$ \\
\hline & 7 & - & $100 \pm 0$ & $85 \pm 28$ & $27 \pm 23$ \\
\hline & 30 & - & $100 \pm 0$ & $76 \pm 23$ & $0 \pm 0$ \\
\hline \multirow[t]{3}{*}{ A. ocbraceus } & 0 & $43 \pm 13$ & $7 \pm 6.6$ & $7 \pm 5 \cdot 7$ & $56 \pm 10$ \\
\hline & 7 & - & $0 \pm 0$ & $16 \pm 13$ & $100 \pm 0$ \\
\hline & 30 & - & $0 \pm 0$ & $100 \pm 0$ & $100 \pm 0$ \\
\hline \multirow[t]{3}{*}{ A. flavus } & 0 & $17 \pm 5$ & $29 \pm 11$ & $41 \pm 42$ & $21 \pm 12$ \\
\hline & 7 & - & $1 \pm 2$ & $0 \pm 0$ & $0 \pm 0$ \\
\hline & 30 & - & $42 \pm 41$ & $52 \pm 35$ & $25 \pm 25$ \\
\hline
\end{tabular}

* Control, uninoculated and unincubated.

Table 4. Changes in level of $P$. aurantiogriseum ExAgs, OA, glucosamine and c.f.u. with time, in non-sterilized and moisturized wheat samples inoculated with different concentrations of $A$. ochraceus spores

ExAgs were quantified using the ELISA. C.f.u., glucosamine and OA were analysed using the procedures of ISO (1983a, b), Rotter et al. (1989), and Clarke et al. (1993), respectively. The correlation coefficients between the concentration of $P$. aurantiogriseum ExAgs and other parameters were: 0.63 $(P<0.05)$ for the number of c.f.u., $0.47(P>0.05)$ for the percentage of Penicillium infection, 0.43 $(P>0.05)$ for glucosamine concentration, $-0.22(P>0.05)$ for the percentage of $A$. ocbraceus infection and $-0.05(P>0.05)$ for $\mathrm{OA}$ concentration, respectively.

Values represent means \pm SD for five replicates.

\begin{tabular}{|c|c|c|c|c|c|}
\hline \multirow[t]{4}{*}{ Parameter } & \multirow{4}{*}{$\begin{array}{c}\text { Incubation } \\
\text { (d) }\end{array}$} & \multicolumn{4}{|c|}{ Level of analysed constituents } \\
\hline & & \multirow{3}{*}{$\begin{array}{l}\text { Control } \\
\text { wheat* }\end{array}$} & \multicolumn{3}{|c|}{ Incubated wheat } \\
\hline & & & \multicolumn{3}{|c|}{ No. of $A$. ochraceus spores $\mathrm{g}^{-1}$ : } \\
\hline & & & 0 & $10^{2}$ & $10^{5}$ \\
\hline \multirow{3}{*}{$\begin{array}{l}\text { P. aurantiogriseum } \\
\text { ExAgs }\left(\mu \mathrm{g} \mathrm{m}^{-1}\right)\end{array}$} & 0 & $0 \cdot 2 \pm 0 \cdot 2$ & $0 \cdot 3 \pm 0 \cdot 05$ & $0 \cdot 09 \pm 0 \cdot 1$ & $0 \cdot 2 \pm 0 \cdot 2$ \\
\hline & 7 & - & $2 \cdot 1 \pm 1 \cdot 1$ & $1 \cdot 3 \pm 0 \cdot 6$ & $1 \cdot 2 \pm 0 \cdot 5$ \\
\hline & 30 & - & $67 \pm 32$ & $13 \pm 6 \cdot 5$ & $7 \cdot 3 \pm 12$ \\
\hline \multirow{3}{*}{ C.f.u. $\left(\log _{10} g^{-1}\right)$} & 0 & $4 \cdot 4 \pm 4 \cdot 2$ & $4 \cdot 2 \pm 3 \cdot 7$ & $3.9 \pm 3.9$ & $4 \cdot 2 \pm 3 \cdot 9$ \\
\hline & 7 & - & $7 \pm 7 \cdot 3$ & $6 \cdot 3 \pm 6$ & $8 \cdot 1 \pm 8 \cdot 2$ \\
\hline & 30 & - & $12 \pm 12$ & $11 \pm 11$ & $12 \pm 12$ \\
\hline \multirow{3}{*}{$\begin{array}{l}\text { Glucosamine } \\
{\left[\text { [mg }(\mathrm{g} \text { grain })^{-1}\right]}\end{array}$} & 0 & $0 \cdot 4 \pm 0.06$ & $0 \cdot 5 \pm 0 \cdot 05$ & $0.4 \pm 0.06$ & $0 \cdot 5 \pm 0 \cdot 1$ \\
\hline & 7 & - & $0.6 \pm 0.05$ & $0 \cdot 7 \pm 0 \cdot 1$ & $1 \cdot 0 \pm 0 \cdot 1$ \\
\hline & 30 & - & $3 \cdot 7 \pm 1$ & $3 \cdot 5 \pm 1$ & $7 \cdot 0 \pm 3$ \\
\hline \multirow[t]{3}{*}{$\mathrm{OA}\left(\mathrm{mg} \mathrm{kg}{ }^{-1}\right)$} & 0 & $0.03 \pm 0.03$ & $0.01 \pm 0.01$ & $0 \pm 0$ & $0 \pm 0$ \\
\hline & 7 & - & $0 \cdot 02 \pm 0 \cdot 02$ & $12 \pm 1$ & $53 \pm 9$ \\
\hline & 30 & - & $0 \cdot 1 \pm 0 \cdot 1$ & $100 \pm 15$ & $130 \pm 7$ \\
\hline
\end{tabular}

* Control, uninoculated and unincubated. 


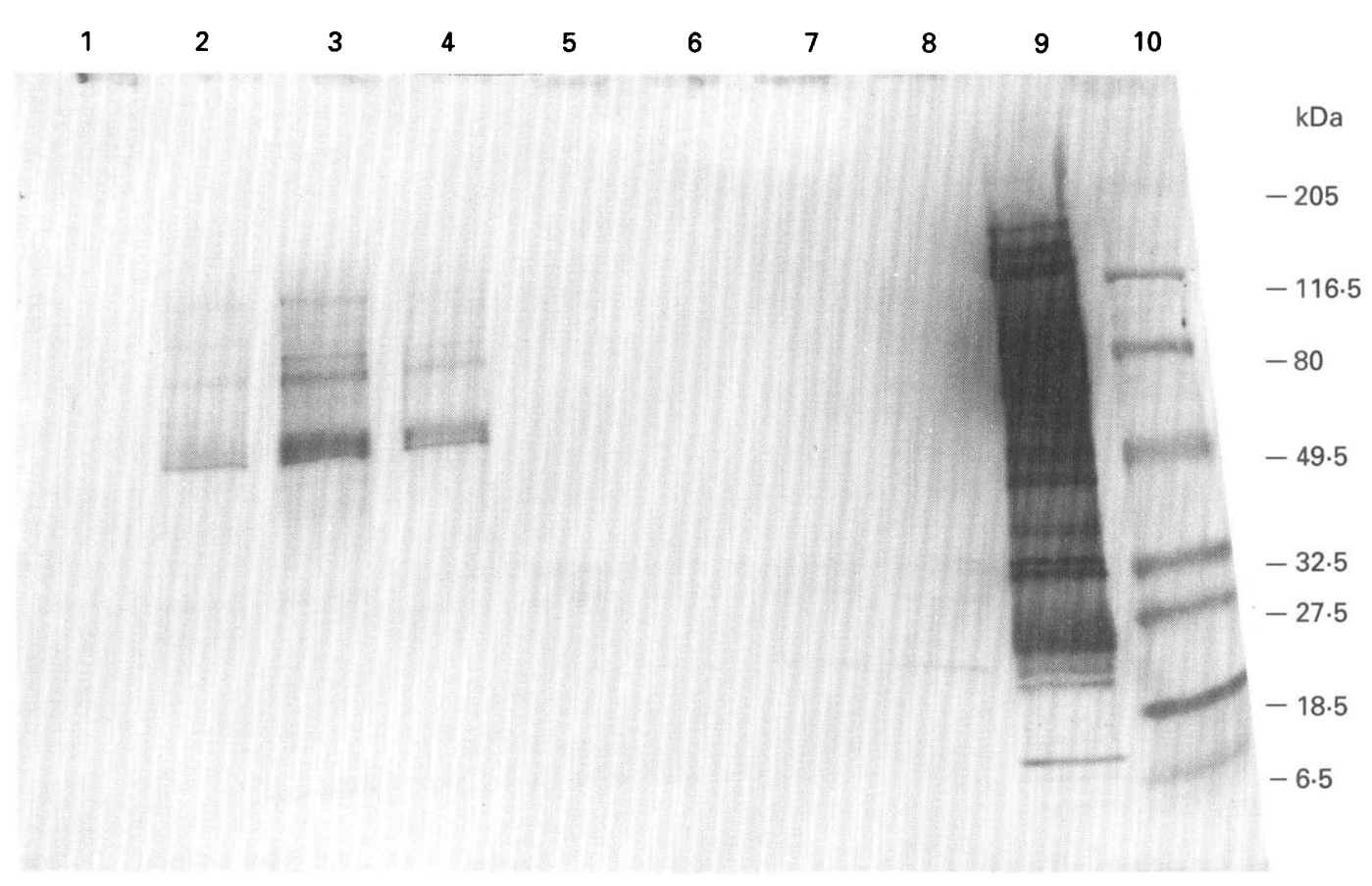

Fig. 3. Immunoblotting detection of ExAgs in mouldy wheat extracts (lanes 1-8) as compared to $P$. aurantiogriseum isolate 3298 ExAgs from liquid culture (lane 9) using rabbit anti-P. aurantiogriseum serum. The specific extracts were control (lane 1); from non-sterilized wheat (replicates in lanes 2, 3 and 4); and non-sterilized wheat inoculated with a low (replicates in lane 5 and 6 ) or a high (replicates in lanes 7 and 8 ) number of $A$. ochraceus spores following the incubation of non-sterilized grain for $30 \mathrm{~d}$. Samples were solubilized by boiling in $1.5 \%$ SDS and separated on 4-15\% gradient gels. Lane 10 contains pre-stained molecular mass standards. See Table 3 and Methods for further detail. The quantity of reference standard $P$. aurantiogriseum ExAgs applied on lane 9 was $1.7 \mu \mathrm{g}$. Replicate analysis gave identical patterns.

that the protein and/or the glycoprotein, and not the carbohydrate components, were primarily responsible for the inhibitory effects of the ExAgs.

\section{Detection of $P$. aurantiogriseum contamination in wheat samples}

Grain naturally infected with fungal spores was inoculated with different concentrations of $A$. ochraceus spores, and the profile of fungal infection was followed after moisturization of the grain and incubation for 0,7 or $30 \mathrm{~d}$ at $30^{\circ} \mathrm{C}$. Analysis of the grain for particular genera and species of fungi prior to incubation demonstrated that it contained spores of Penicillium spp., A. ocbraceus and $A$. flavus (Table 3). A visual inspection of the grain indicated that there was considerable mould growth in all samples after $7 \mathrm{~d}$ incubation and very pronounced growth after $30 \mathrm{~d}$. A dramatic increase in contamination of grain with Penicillium spp. (21 to $100 \%$ ) occurred when moisturized, uninoculated grain was incubated for $30 \mathrm{~d}$. There was a corresponding decrease in $A$. ochraceus ( 7 to $0 \%$ ) and an increase in $A$. flavus ( 29 to $42 \%$ ) contaminations. Samples in the different treatments were also analysed for total number of c.f.u. and glucosamine as indicators of total fungal biomass in the grain, and for $\mathrm{OA}$ and $P$. aurantiogriseum ExAgs as indicators of the presence of $A$. ocbraceus and $P$. aurantiogriseum, respectively (Table 4). The data showed that the concentration of $P$. aurantiogriseum ExAgs in naturally infected (uninoculated) grain, as detected by the ELISA, increased dramatically during the time course of the study, from $0.3 \mu \mathrm{g} \mathrm{m}^{-1}$ in the unincubated wheat to $67 \mu \mathrm{g} \mathrm{ml}^{-1}$ after $30 \mathrm{~d}$. This increase was accompanied by increases in the concentration of glucosamine, an indicator of fungal mass, and c.f.u. but not in the concentration of OA. In contrast, samples of grain which were inoculated with $A$. ochraceus spores and incubated for 7 or $30 \mathrm{~d}$ showed a much lower increase in the concentration of $P$. aurantiogriseum ExAgs (a maximum difference of 10 -fold), but a great increase in OA concentration (maximum difference of 300 -fold). The glucosamine content and the number of c.f.u. in inoculated groups increased dramatically (e.g. 0.5 to $7 \cdot 0 \mathrm{mg}$ for glucosamine, and $10^{4}$ to $10^{12}$ c.f.u. per g grain) and were similar to each other and to those in the uninoculated samples after $30 \mathrm{~d}$ of incubation. The concentration of $P$. aurantiogriseum ExAgs in the grain samples was positively correlated with the c.f.u. counts (footnotes of Table 4; $r=0.63, P<0.05)$. The correlation coefficients between the concentration of $P$. aurantiogriseum ExAgs and the other parameters were much lower $(P>0.05)$.

The results of immunoblotting on selected wheat samples 
showed that the rabbit anti- $P$. aurantiogriseum serum detected more antigens in samples where Penicillium predominated than in samples where $A$. ochraceus predominated (Fig. 3), and did not react with control (uninoculated and unincubated) wheat. The immunoblotting pattern of $P$. aurantiogriseum ExAgs obtained from liquid culture had a similar pattern to those obtained from the wheat extracts prepared from inoculated grain. The same antigenic bands were present in all samples; except some which were present at very low levels as indicated by the faint bands. These results are consistent with the concentration of $P$. aurantiogriseum ExAgs (Table 4) that was detected using the ELISA. They demonstrate that the growth of $P$. aurantiogriseum in wheat naturally infected with this fungus was suppressed when the wheat was inoculated with $A$. ochraceus.

\section{DISCUSSION}

The ELISA employed in this study demonstrated that the rabbit anti- $P$. aurantiogriseum serum was specific for $P$. aurantiogriseum, and that it had little or no cross-reactivities with five other Penicillium species, four species of $A s$ pergillus, three Fusarium species, two Mucor species and one Alternaria species. The ExAg profiles obtained by immunoblotting following SDS-PAGE also confirmed these observations, as there were at least 15 common bands among $P$. aurantiogriseum isolates, and at most only a few of these bands (one or two) were common to other species. Immunoblotting analysis was a particularly useful tool, as it not only detected the presence of very small quantities of antigens, but also revealed some physicochemical properties of the antigenic components. The potential usefulness of the ELISA was further confirmed in naturally infected wheat that was inoculated with $A$. ochraceus spores. There was a dramatic increase in total fungal biomass for all treatments after a $30 \mathrm{~d}$ incubation period as indicated by the glucosamine level and the number of c.f.u., with the final composition of fungi being influenced by the degree of infection with $A$. ochraceus. Grain samples that had a high percentage of Penicillium had a much higher concentration of the $P$. aurantiogriseum ExAgs than those that had a high percentage of $A$. ochraceus.

The results from this study therefore suggest that antibodies against the ExAgs from $P$. aurantiogriseum can be used to specifically detect $P$. aurantiogriseum in the presence of other species of Penicillium or other genera of fungi, and that the method is reproducible and sensitive, with the detection limit being as low as $50 \mathrm{ng} \mathrm{ExAg}$ protein $\mathrm{ml}^{-1}$. In addition, anti- $P$. aurantiogriseum serum did not cross-react with water-soluble plant proteins (wheat, barley, maize and soybean), indicating that $P$. aurantiogriseum ExAgs ELISA can be used to specifically detect this fungus in a plant matrix. Several other researchers have also developed ELISA for the detection of common moulds in foods, including Mucor, Fusarium, Aspergillus and Penicillium (Notermans \& Heuvelman, 1985), Alternaria, Geotrichum and Rhizopus in tomato purée (Lin et al., 1986), and Cladosporium, Geotrichum and
Mucor in dairy products (Tsai \& Cousin, 1990). All of these assays appear to have limitations, as they are not species- or even genus-specific (Notermans \& Kamphuis, 1992; Van der Horst et al., 1992; Banks et al., 1993). One possible reason for this lack of specificity is that in these studies the antigens were mostly heat-stable and may be polysaccharide in nature. These polysaccharides are not only present in several fungal genera, but may also be present in food products such as walnuts (Preston et al., 1970; Notermans \& Kamphuis, 1992; Van der Horst et al., 1992). One exception is the monoclonal-antibodybased ELISA and 'DIP-STICK'-type assay for $P$. islandicum that was developed by Dewey et al. (1990). The antibody was generally species-specific, and the assay may be considered to be the first species-specific assay that has been developed for the detection of Penicillium species in grain.

The ExAgs used in this study were a mixture of excreted macromolecules $(10-120 \mathrm{kDa})$, their nature being generally unknown. Ammonium sulfate fractionation, however, demonstrated that they may have been composed of proteins, glycoproteins and carbohydrates, with most of the reactivity of the anti- $P$. aurantiogriseum serum being attributable to the former two rather than the latter component of the ExAgs. Among the many protein bands that were separated by electrophoresis, only three or four, of molecular mass $70-90 \mathrm{kDa}$, were immunodominant. Purification of ExAgs, and possibly the use of monoclonal antibody, may therefore be necessary for developing more specific assays. The ExAgs, nevertheless, appear to be particularly useful immunogens, as extraction procedures are simple, they appear to be unique for certain fungal species and they can be readily utilized in an ELISA format.

Previous studies, however, have been inconclusive with regard to the nature of the antigens obtained from fungal extracts. Polonelli et al. (1986), working with the ExAgs of Microsporum canis, reported that the antigenic components in isolates of this species were protein in nature and could be utilized for immunoidentification and typing of dermatophytes. Yu et al. (1990), in studies with homogenates of $A$. fumigatus, also concluded that the antigens from this fungus were protein. Hearn et al. (1990) concluded that the electrophoretically separated antigenic moieties from $A$. fumigatus mycelial extracts were predominantly glycoprotein, and that both carbohydrate and protein residues were involved in the binding of the antigen to the antibody. Similarly, MacDonald et al. (1989) demonstrated that the low molecular mass surface glycoproteins were the major specific antigens in different species of fungi. Notermans \& Kamphuis (1992), as discussed above, developed antibodies against extracellular polysaccharides.

The procedure for producing the ExAgs is simple, and antiserum against the ExAgs can be readily produced in rabbits, the yolk of the laying hen (unpublished data), and probably other animal species in large amounts. The antibodies can be used in an ELISA, for immunoblotting studies and probably in a double-diffusion assay as 
originally used by Kaufman \& Standard (1987). As a result, this procedure can be used under a wide variety of conditions, and could be readily adapted to conditions in third-world countries as the requirement for equipment is minimal and the cost per assay is low. It is concluded that the ExAgs-ELISA and immunoblotting tests are sensitive, quantitative and sufficiently specific to be used for the identification and detection of $P$. aurantiogriseum and closely related species in cereal grains. Further studies on a broader spectrum of fungi, under different growth conditions, are needed to show that the ELISA developed in this study can be used for routine screening of $P$. aurantiogriseum contamination in grain. The results also suggest that the ExAgs can be used to develop similar specific assays for other toxicologically important fungi. Recent studies in our laboratory have demonstrated that solid-phase immunoassays of $A$. ochraceus ExAgs were also specific and could be used to detect the presence of this fungus in stored grain (Lu et al., 1994).

\section{ACKNOWLEDGEMENTS}

The authors are grateful for Mrs N. Wang, Mrs S. Li, Mr J. R. Clarke and Mr R. M. Clear for their assistance. We also thank Natural Sciences and Engineering Research Council (NSERC) of Canada, Manitoba Agriculture and the University of Manitoba for financial support of this research programme. Partial support for this study was provided by the University of Manitoba Graduate Fellowship to P.L.

\section{REFERENCES}

Banks, J. N., Cox, S. J. \& Northway, B. J. (1993). Polyclonal and monoclonal antibodies to field and storage fungi. Int Biodeterior \& Biodegrad 32, 137-144.

Blake, M. S., Johnstone, K. H., Russell-Jones, G. J. \& Gotschlich, E. C. (1984). A rapid, sensitive method for detection of alkaline phosphatase-conjugated anti-antibody on Western blots. Anal Biocbem 136, 175-179.

Bradford, M. M. (1976). A rapid and sensitive method for the quantitation of microgram quantities of protein utilizing the principle of protein-dye binding. Anal Biochem 72, 248-254.

CAST (1989). Mycotoxins: Economic and Health Risks. Ames, Iowa: Council for Agricultural Science and Technology.

Clarke, J. R., Marquardt, R. R., Oosterveld, A. \& Frohlich, A. A. (1993). Development of a quantitative and sensitive enzyme-linked immunoassay for ochratoxin A using antibodies from the yolk of the laying hen. J Agric Food Cbem 41, 1784-1789.

Dewey, F. M., MacDonald, M. M., Phillips, S. I. \& Priestley, R. A. (1990). Development of monoclonal-antibody-ELISA and -DIPSTICK immunoassays for Penicillium islandicum in rice grains. $J$ Gen Microbiol 136, 753-760.

Dubois, M., Gilles, K. A., Hamilton, J. K., Rebers, P. A. \& Smith, F. (1956). Colorimetric method for determination of sugars and related substances. Anal Chem 28, 350-356.

Frisvad, J. C. (1988). Fungal species and their specific production of mycotoxins. In Introduction to Food-borne Fungi, pp. 239-249. Edited by R. A. Samson \& E. Van Reenen-Hoekstra. Baarn: Centralbureau Voor Schimmelcultures.
Frisvad, J. C. (1989). The connection between the penicillia and aspergilli and mycotoxins with special emphasis on misidentified isolates. Arch Environ Contam Toxicol 18, 452-467.

Frisvad, J. C. \& Filtenborg, O. (1989). Terverticillate Penicillia: chemotaxonomy and mycotoxin production. Mycologia 81, 837-861.

Fuhrmann, B., Roquebert, M. F., Lebreton, V. \& Van Hoegaerden, M. (1990). Immunological differentiation between Penicillium and Aspergillus taxa. In Modern Concepts in Penicillium and Aspergillus Classification, pp. 423-432. Edited by R. A. Samson \& J. I. Pitt. New York: Plenum Press.

Fuhrmann, B., Lebreton, V., Van Hoegaerden, M., Kamphuis, H. J. \& Strosberg, A. D. (1992). A monoclonal antibody specific for conidia and mycelium wall layer of Penicillium and Aspergillus. Microbiol Immunol 36, 1-12.

Harlow, E. \& Lane, D. (1988). Antibodies : a Laboratory Manual. Cold Spring Harbor, NY: Cold Spring Harbor Laboratory.

Hearn, V. M., Wilson, E. V., Latge, J.-P. \& MacKenzie (1990). Immunological studies on Aspergillus fumigatus mycelial antigens by polyacrylamide gel electrophoresis and Western blotting techniques. J Gen Microbiol 136, 1525-1535.

International Organization for Standardization (ISO) (1983a). 6887E Microbiology - general guidance for the preparation of dilutions for microbiological examination.

International Organization for Standardization (ISO) (1983b). TC34/SC4/WG2 Grain, seeds and derived products - Microbiological examination - Colony count technique.

Jarvis, B. \& Williams, A. P. (1987). Methods for detecting fungi in foods and beverages. In Food and Beverage Mycology, 2nd edn, pp. 599-636. Edited by L. R. Beuchat. New York: Van Nostrand Reinhold.

Jarvis, B., Seiler, D. A. L., Ould, A. J. L. \& Williams, A. P. (1983). Observations on the enumerations of molds in food and feedingstuffs. J Appl Bacteriol 55, 325-336.

Kaufman, L. \& Standard, P. G. (1987). Specific and rapid identification of medically important fungi by exoantigen detection. Annu Rev Microbiol 41, 209-225.

Laemmli, U. K. (1970). Cleavage of structural proteins during the assembly of the head of bacteriophage T4. Nature 227, 680-685.

Lin, H. H., Lister, R. M. \& Cousin, M. A. (1986). Enzyme-linked immunosorbent assay for detection of mold in tomato puree. $J$ Food Sci 51, 180-192.

Lu, P., Marquardt, R. R., Frohlich, A. A. \& Mills, J. (1994). The development of a solid-phase immunoassay for the detection and identification of Aspergillus ochraceus. Food Agric Immunol (in press).

Lund, F. \& Frisvad, J. C. (1994). Chemotaxonomy of Penicillium aurantiogriseum and related species. Mycol Res (in press).

MacDonald, M. M., Dunstan, R. H. \& Dewey, F. M. (1989). Detection of low- $M_{\mathrm{r}}$ glycoproteins in surface washes of some fungal cultures by gel-filtration HPLC and by monoclonal antibodies. J Gen Microbiol 135, 375-383.

Mills, J. T. \& Wallace, H. A. H. (1979). Microflora and condition of cereal seeds after a wet harvest. Can J Plant Sci 59, 645-651.

Mills, J. T., Frisvad, J. C., Seifert, K. A. \& Abramson, D. (1994). Identification of nephrotoxic Penicillium species from cereal grains. Mycotoxin Res (in press).

Notermans, S. \& Heuvelman, C. J. (1985). Immunological detection of molds in food by using the enzyme-linked immunosorbent assay (ELISA); preparation of antigens. Int J Food Microbiol 2, 247-258.

Notermans, E. \& Kamphuis, H. J. (1992). Detection of fungi in foods by latex agglutination: a collaborative study. In Modern 
Methods in Food Mycology, pp. 205-212. Edited by R. A. Samson, A. D. Hocking, J. I. Pitt \& A. D. King. Amsterdam: Elsevier.

Notermans, S., Heuvelman, C. J., van Egmond, H. P., Paulsch, W. E. \& Besling, J. R. (1986). Detection of mold in food by enzymelinked immunosorbent assay. J Food Prot 49, 786-791.

Pitt, J. I. \& Hocking, A. D. (1985). Fungi and Food Spoilage. Sydney: Academic Press.

Pitt, J. I. \& Samson, R. A. (1990). Approaches to Penicillium and Aspergillus systematics. Stud Mycol 32, 77-90.

Polonelli, L., Castagnola, M. \& Morace, G. (1986). Identification and serotyping of Microsporum canis isolates by monoclonal antibodies. J Clin Microbiol 23, 609-615.

Preston, J. F., III, Lapis, E. \& Gander, J. E. (1970). Immunological investigations of Penicillium. I. Serological reactivities of exocellular polysaccharides produced by six Penicillium species. Can J Microbiol 16, 687-694.

Rotter, R. G., Frohlich, A. A., Marquardt, R. R. \& Mills, P. A. (1989). Estimation of fungal contamination of cereal grains as determined by measuring glucosamine concentration. Can J Anim Sci 69, 235-245.
Samson, R. A. \& Frisvad, J. C. (1991). Current taxonomic concepts in Penicillium and Aspergillus. In Cereal Grains: Mycotoxins, Fungi and Quality in Drying and Storage, (Dev Food Sci. vol. 26), pp. 405-439. Edited by J. Chelkowski. Amsterdam: Elsevier.

Standard, P. G., Kaufman, L. \& Whaley, S. D. (1985). Rapid Identification of Patbogenic Mold Isolates by Immunodiffusion (CDC Lab. Manual). Atlanta, GA: Centers for Disease Control.

Tsai, G.-J. \& Cousin, M. A. (1990). Enzyme-linked immunosorbent assay for detection of molds in cheese and yogurt. J Dairy Sci 73, 3366-3378.

Van der Horst, M., Samson, R. A. \& Karman, H. (1992). Comparison of two commercial kits to detect molds by latex agglutination. In Modern Methods in Food Mycology, pp. 241-245. Edited by R. A. Samson, A. D. Hocking, J. I. Pitt \& A. D. King. Amsterdam: Elsevier.

Yu, B., Niki, Y. \& Armstrong, D. (1990). Use of immunoblotting to detect Aspergillus fumigatus antigen in sera and urine of rats with experimental invasive aspergillosis. J Clin Microbiol 28, 1575-1579.

Received 8 August 1994; accepted 7 September 1994. 